EESTI NSV TEADUSTE AKADEEMIA TOIMETISED. XIII KOIDE FCOSIKA-MATEMAATIKA- JA TEHNIKATEADUSTE SEERIA. 1964, NR. 4

ИЗВЕСТИЯ АКАДЕМИИ НАУК ЭСТОНСКОН ССР. ТОМ ХІІ СЕРИЯ ФИЗИКО-МАТЕМАТИЧЕСКИХ И ТЕХНИЧЕСКИХ НАУК. 1964, № 4

\title{
УМЕНЬШЕНИЕ СОПРОТИВЛЕНИЯ ЗАЗЕМЛЕНИЯ ПРИ ПОМОЩИ СУСПЕНЗИЙ ГЛИНЫ
}

\section{X. РАБА}

Заземления в песчаных грунтах с глубоко лежащей подпочвенной водой имеют, как известно, высокие, часто не соответствующие действующим нормам величнны сопротивления $\left(R_{3}\right)$. Несмотря на многочисленные работы $\left[{ }^{1-6}\right]$ в области уменьшения $R_{3}$, этот вопрос остается нерешенным и актуальным до сего времени. Чтобы добиться уменьшения $R_{3}$, прибегают к различным методам, которые сводятся либо к увеличению количества заземлителей, либо к обработке почвы. В последнем случае в грунт помешают большие количества хорошо проводящих веществ, например, поваренную соль, соду, медный купорос и т. п., или заменяют часть грунта другим веществом, имеющим сильно выраженные абсорбционные свойства, например, шлаком, торфом и др.

Особенностью песка (в меньшей степени супеска) является большая водопроницаемость и отсутствие в нем водорастворимых органических соединений и солей. Вода осадков, просачиваясь в грунт, вследствие большой водопроницаемости не удерживается в зоне расположения заземлителей, а быстро устремляется к нижележащим грунтовым водам. Поэтому в подобных грунтах величина удєльного сопротивления (@) подвергнута не только сезонным, но даже ежедневным значительным колебаниям в зависимости от осадков [9]. Этот факт крайне нежелателен с точки зрения надежности защиты энергетических объектов. Как известно, е воды осадков находится в пределах $0,1 \div 0,5$. - $10^{2}$ ом $\cdot\left[^{4}\right]$ и может быть понижено прибавлением примесей только до ее насыщения. Насышение воды поваренной солью достигается, например, при $60-70$ г поваренной соли на $1 \Omega$ воды [3]. Поскольку нет данных о необходимом в каждом конкретном случае количестве соли и, учитывая кратковременность ее действия в песчаном грунте, использо-

Таблица

\begin{tabular}{r|c}
\hline $\begin{array}{c}\text { Koнцентрация: } \\
\text { суспензии, } 2 / \Omega\end{array}$ & $\begin{array}{c}\text { Удельное } \\
\text { сопротивление } \\
\text { суспензии, } \\
10^{-2} \text { оль } \cdot \text { м }\end{array}$ \\
\hline 60 & 799 \\
80 & 676 \\
100 & 596 \\
150 & 830 \\
200 & 838
\end{tabular}
вание вышеприведенных физико-химических методов обработки нужно считать нерациональным.

Суспензия глины представляет собой механическую смесь обыкновенной водопроводной воды и глины. Удельное сопротивление такой суспензии зависит от количества растворенной в ней глины и является наименьшим при насыщении суспензии, т. е. при концентрации 100 г/л (табл. 1). 
Таблица 2

Суспензия на основе обыкновенной воды (концентрация $100 \mathrm{z} / \Omega$, удельное сопротивление $\left.\varrho=596 \cdot 10^{-2} O M \cdot \leftrightarrow\right)$

\begin{tabular}{|c|c|c|c|c|}
\hline $\begin{array}{c}\text { Прибавляемые } \\
\text { химнкалин }\end{array}$ & $\begin{array}{c}\text { Количество } \\
\text { добавки, } \\
2 / \Omega\end{array}$ & $\mathrm{pH}$ & $\begin{array}{c}\frac{M}{t} \\
C A^{3} / 4 a c\end{array}$ & $\begin{array}{c}\text { Удельное } \\
\text { сопротивление, } \\
10^{-2} \text { ом } \cdot \mu\end{array}$ \\
\hline $\mathrm{NaCl}$ & $\begin{array}{l}1 \\
2 \\
5 \\
7\end{array}$ & $\begin{array}{l}9,6 \\
9,5 \\
9,3 \\
9,1\end{array}$ & $\begin{array}{l}28,4 \\
33 \\
37,2 \\
45\end{array}$ & $\begin{array}{r}329 \\
255 \\
115 \\
87\end{array}$ \\
\hline $\mathrm{Na}_{2} \mathrm{CO}_{3}$ & $\begin{array}{l}1 \\
2 \\
4\end{array}$ & $\begin{array}{l}10,0 \\
10,1 \\
10,2\end{array}$ & $\begin{array}{l}20,2 \\
21 \\
22\end{array}$ & $\begin{array}{l}408 \\
312 \\
241\end{array}$ \\
\hline $\mathrm{NaOH}$ & $\begin{array}{l}1 \\
2 \\
4\end{array}$ & $\begin{array}{l}10,6 \\
11,7 \\
12,1\end{array}$ & $\begin{array}{l}20,2 \\
23 \\
23,4\end{array}$ & $\begin{array}{l}404 \\
235 \\
185\end{array}$ \\
\hline
\end{tabular}

Суспензия на основе промышленных отходов (концентрацня 100 г/ $\Omega$, без добавок)

\begin{tabular}{l|c|c|c}
\hline Сернокислое железо & 9,7 & 19 & 312,5 \\
\hline Сульфитный щелок & 10,0 & 17,5 & 270 \\
\hline Щелочная вода & 10,2 & 16,1 & 170
\end{tabular}

Обработка суспензиями некоторого объема почвы вокруг заземлителя образует стабильно действующую, имеющую коллоидные свойства систему. В дождливое время коллоидная система накапливает влагу осадков, отдавая єе в засушливый период окружающей почве, сохраняя тем самым в зоне укладки заземлителя повышенную влажность и обеспечивая на сравнительно долгое время стабильные уменьшенные величины $R_{3}$.

Двухлетние периодические измерения сопротивления почвы вокруг сосредоточенных и протяженных заземлителей, проведенные после ее обработки суспензиями глины на основе обыкновенной водопроводной воды с $\varrho=0,5 \cdot 10^{2}$ ом.$\mu$ показывают, что в результате такой обработки $R_{3}$ уменьшается в среднем в $2-3$ раза и отличается стабильностью независимо от атмосферных влияний [ $\left.{ }^{11}\right]$.

Последующие исследования показали, что прибавление к суспензии незначительных количеств $\mathrm{Na}_{2} \mathrm{CO}_{3}, \mathrm{NaOH}, \mathrm{NaCl}$ и других химикалий шелочной реакции делает возможным дальнейшее уменьшение $\varrho$ и водопроводности суспензии. Еце лучших результатов можно достигнуть путем применения вместо воды промышленных отходов (вод) ряда предприятий. Самыми перспективными из них оказываются щелочная вода (известная также под названием «черный щелок»), сульфитный щелок и сернокислое железо $\left(\mathrm{FeSO}_{4}\right)$. Первые два отхода получаются в неограниченном количестве на целлюлозно-бумажных комбинатах и представляют собой смесь нескольких химических соединений щелочной реакции, органических веществ и воды, третий является отходом метал„ообрабатывающих предприятий. Многолетний опыт показывает, что 
все эти промышленные отходы практически не действуют на материал заземлителей из стали, железа и красной меди.

Об изменении водопроницаемости суспензий глин в зависимости от их концентрации и количества прибавляемых химикалий в лабораторных условиях можно судить путем измерения количества фильтрата $M$ фильтр-пресса, проходящего за определенное время $t$ через объем суспензии поверхностью $S$ и толщиной $h$ под давлением $p$, т. е.

Таблица 3

\begin{tabular}{|c|c|c|c|c|c|c|}
\hline \multirow{3}{*}{ 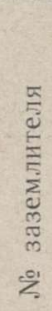 } & \multicolumn{6}{|c|}{$\mathrm{Cycn}$} \\
\hline & \multirow{2}{*}{ 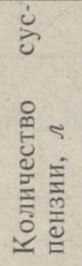 } & \multirow{2}{*}{ 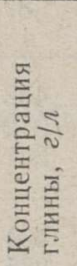 } & \multicolumn{2}{|c|}{$\begin{array}{l}\text { Cопротив- } \\
\text { ление зазем- } \\
\text { ления, ком }\end{array}$} & \multirow{2}{*}{$\frac{R_{3}^{\prime \prime}}{R_{3}^{\prime}}$} & \multirow{2}{*}{$\begin{array}{l} \\
0 \\
0 \\
0 \\
\delta\end{array}$} \\
\hline & & & $R_{3}^{\prime}$ & $R_{3}^{\prime \prime}$ & & \\
\hline & \multicolumn{5}{|c|}{ Почва не обработан } & 102 \\
\hline $\begin{array}{r}13 \\
6 \\
1 \\
2 \\
4 \\
5 \\
7\end{array}$ & $\begin{array}{l}200 \\
200 \\
200 \\
300 \\
300 \\
300 \\
300 \\
300 \\
300\end{array}$ & $\begin{array}{r}25 \\
25 \\
35 \\
50 \\
50 \\
100 \\
100 \\
100 \\
100\end{array}$ & 4,2 & $\begin{array}{l}3,9 \\
3,8 \\
2,8 \\
1,0 \\
0,9 \\
0,78 \\
0,84 \\
0,64 \\
0,30\end{array}$ & $\begin{array}{l}0,93 \\
0,90 \\
0,67 \\
0,24 \\
0,21 \\
0,18 \\
0,20 \\
0,15 \\
0,07\end{array}$ & $\begin{array}{l}96 \\
93 \\
68 \\
24 \\
22 \\
19 \\
18,5 \\
14 \\
6,6 *\end{array}$ \\
\hline
\end{tabular}

* Вычислено по формуле Вайнера $\left[{ }^{9}\right]$

$$
\varrho=\frac{2 \pi l R_{3}}{\ln \frac{2 l}{d}+\frac{1}{2} \ln \frac{2 t+l / 2}{2 t-l / 2}} \cdot \text { Здесь } t=h+\frac{l}{2} \text {. }
$$

** Қ суспензии прибавлен таннин в количе стве 1 2/.2. $R_{3}$ измерялось, меггером и измерителем заземления типа МС-07 два раза в месяц. Обработка суспензией снижает $R_{3}$ трубчатых заземлителей до пяти раз. Как показывают результаты более двухлетних периодических измерений, достигнутые величины $R_{3}$ являются довольно стабильными (рис. 2).

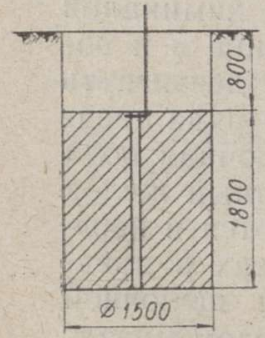

a)

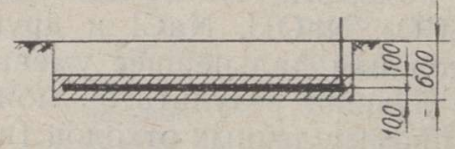

б)

Рис. 1. Подлежащий обработке объем песчаной почвы вокруг a - сосредоточенного, 6 протяженного заземлителя.

$$
\frac{M}{t}=A\left(\frac{p S}{h}\right)
$$

где $A$ - водопроницаемость суспензии. При постоянных $p, S$ и $h$

$$
\frac{M}{t} \approx A
$$

В табл. 2 приведены данные измерения $\frac{M}{t}$ и $\varrho$ суспензий глины, содержаших 100 г глины на $1 \Omega$ вышеуказанных промышленных отходов (вод). В целях сравнения эффекта в той же таблице приведены соответствующие величины для суспензий такой же концентрации $(1002 / \Omega)$, но на основе обыкновенной водопроводной воды с прибавлением незначительных количеств химикатов щелочной реакции.

Из табл. 2 видно, что с увеличением количества $\mathrm{NaCl}$ водопроницаемость суспензий не уменышается, как этого можно было ожидать, а наоборот, увеличивается. Объясняется это коагуляцией (распадом) частиц глины. Поэтому применение $\mathrm{NaCl}$ в суспензиях глины не может быть рекомендовано.

Влияние суспензий глины на величину $R_{3}$ было исследовано на опытных заземлениях, расположенных в песках и супесках. 


\section{Сосредоточенные заземлители в песке}

В качестве сосредоточенных заземлителей использованы стальные трубы внешним диаметром $d=13 / 4^{\prime \prime}$ и длиной $l=1,8 \mathrm{M}$, вертикально забитые в чисто песчаный грунт (пласт песка толщиной около $9-10$ м) на глубину $h=0,8$ м (рис. $1 a$ ). Пользуясь органическими, растворимыми в песчаных грунтах вешествами, например, таннином, представляется возможным уменьшить вязкость суспензий и добиться удовлетворительного ее проникновения в піочву. Следует рекомендовать суспензии большей вязкости для гравия и меньшей для мелкозернистого песка. Результаты обработки песка вокруг трубчатых заземлителей приведены в табл. 3, где $R_{3}^{\prime}$ - минимальное значение $R_{3}$ в летний период, $R_{3}^{\prime \prime}$ - среднее значение $R_{3}$ после обработки.

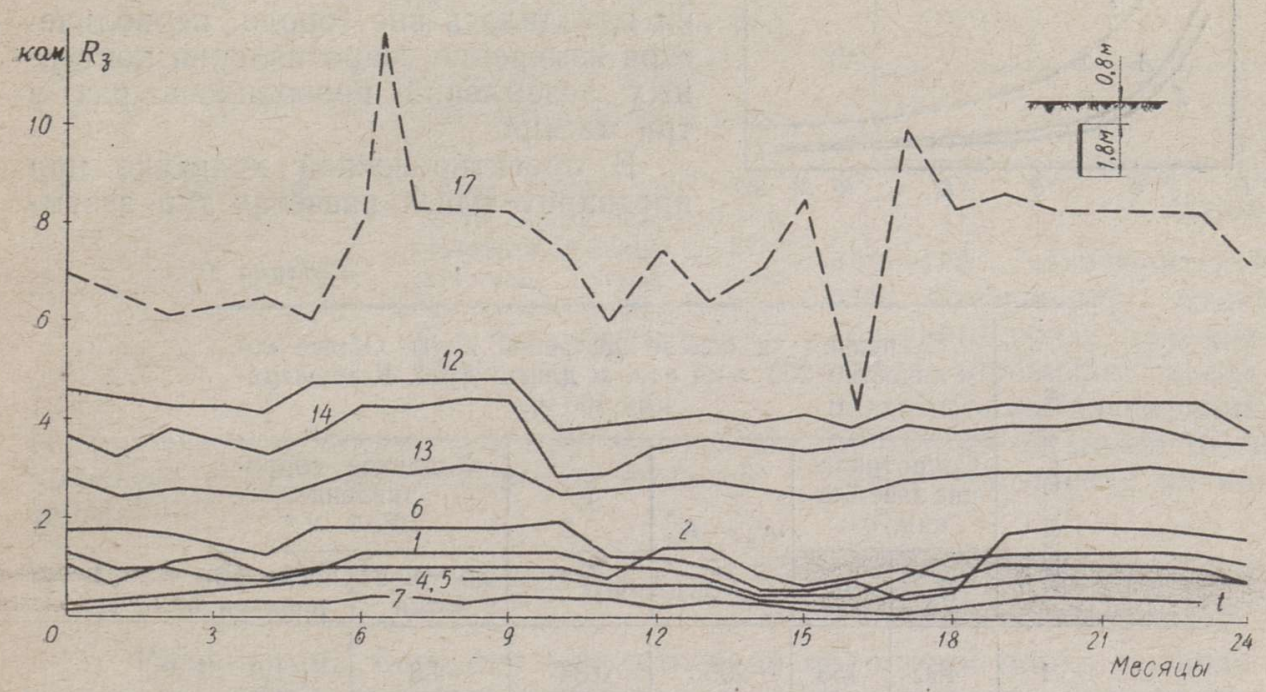

Рис. 2. Зависимость сопротивления заземления сосредотоненных заземлителей, обработанных суспензиями глины (по данным табл. 3), от времени.

\section{Протяженные заземлители (лучи) в супеске}

Протяженные заземлители представляют собой лучи различной длины, изготовленные из стальной оцинкованной проволоки диаметром $d=6$ мм и длиной (l) до $40 \mu$. Лучи были заложены горизонтально в канавы на глубину $t=0,5 \mu$ (рис.1б). Толщина пласта супеска в этих местах не превышала $1-2$ м. Под супеском находилась массивная скала (известняк). На основании результатов измерений, приведенных в табл. 4 , можно заключить, что разность $R_{3}^{\prime}-R_{3}^{\prime \prime}$ является наибольшей при сравнительно коротких (до 8 м) лучах. Как видно из рис. 3 , обработка суспензией снижает величину $R_{3}$ в три раза.

\section{Контурные заземления мачт ВЛ $35 \kappa 8$}

Контурные заземления представляли собой четыре вертикально забитые в почву трубчатых заземлителя диаметром $d=2^{\prime \prime}$, соединенных полосами сечением $25 \times 4$ мм по схеме рис. 4 . Обработке подвергалась почва только вокруг вертикальных заземлителей, причем производилась 


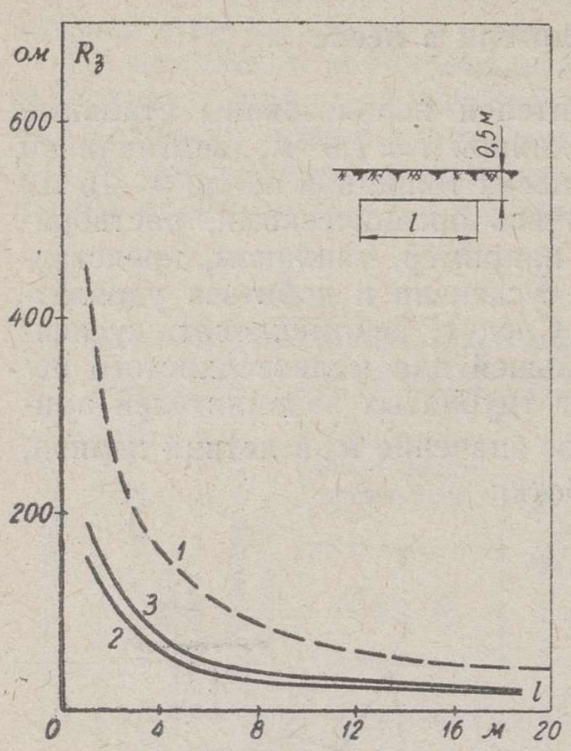

Рис. 3. Зависимость сопротивления заземле. ния протяженных заземлителей, обработанных суспензией глины (по данным табл.4), от длины заземлителя. Величина $F_{3}: 1$ - до обработки, 2 - после обработки, 3 - после двухлетнего пребывания в почве

она при тех же условиях, что и для одиночных труб: суспензия на основе щелочной воды, количество - $300 \Omega$, концентрация - 100 2/ $\Omega$.

Обработка контурных заземлений мачт снижала $R_{3}$ примерно в плть раз. Поскольку линия электроперелачи находилась вне города, периодиче. ское измерение сопротивления контурных заземлений проводилось раз в три месяца.

В проектировочной практике при предварительных расчетах тип зазем-

Таблица 4

\begin{tabular}{|c|c|c|c|c|c|c|}
\hline \multirow{3}{*}{ 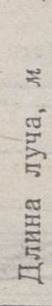 } & \multicolumn{6}{|c|}{$\begin{array}{c}\text { Суспензия на основе шелочной воды. Общее ко- } \\
\text { личество } 300 \Omega \text { на пог. } м \text { длины луча. Концентра- } \\
\text { ция } 100 \mathrm{z} / \Omega\end{array}$} \\
\hline & \multicolumn{2}{|c|}{$\begin{array}{l}\text { Сопротивле- } \\
\text { ние заземле- } \\
\text { ния, ом }\end{array}$} & \multirow[t]{2}{*}{$R_{3}^{\prime}-R_{3}^{\prime \prime}$} & \multirow{2}{*}{$\frac{R_{3}^{\prime \prime}}{R_{3}^{\prime}}$} & \multicolumn{2}{|c|}{$\begin{array}{c}\text { Удельное сопро- } \\
\text { тивление, } \\
10^{2} \text { OM. } M^{*}\end{array}$} \\
\hline & $R_{3}^{\prime}$ & $R_{3}^{\prime \prime}$ & & & $\begin{array}{c}\text { до обра- } \\
\text { ботки }\end{array}$ & $\begin{array}{c}\text { после об- } \\
\text { работки }\end{array}$ \\
\hline 1 & 450 & 155 & 295 & 0,34 & 4.8 & 1,6 \\
\hline 2 & 290 & 100 & 190 & 0,34 & 5,0 & 1,7 \\
\hline 3 & 200 & 75 & 125 & 0,37 & 4,7 & 1,8 \\
\hline 4 & 170 & 60 & 110 & 0,35 & 4,9 & 1,7 \\
\hline 8 & 86 & 31 & 55 & 0,36 & 4,3 & 1,6 \\
\hline 12 & 65 & 24 & 41 & 0,37 & 4,5 & 1,6 \\
\hline 16 & 50 & 17 & 33 & 0,34 & 4,3 & 1,5 \\
\hline 20 & 45 & 16 & 29 & 0,35 & 4,7 & 1,7 \\
\hline
\end{tabular}

* Вычислена по формуле Найфельда [10]

$$
\mathrm{Q}=\frac{2,7 \cdot l \cdot R_{3}}{\lg \frac{l^{2}}{t \cdot d}}
$$

ліения выбирается по величине удельного сопротивления почвы на месте укладки сооружаемого заземления. В каждом ответственном случае эту-величину следует предвағительно определить. Руководствуясь классификацией грунтов по удельному сопротивлению, приведенной в табл. $5[7,8]$, применяются типовые заземления группы, соответствующей величине удельного сопротивления, полученной после обработки почвы. В нашем случае представляется возможным применять в песке заземления 4-й группы, а в супеске-2-й группы, чем достигается заметная экономия строительных материалов и монтажных работ без ущерба для надежности работы заземлений.

Особенное значение описываемый метод имеет для уменьшения ко- 
Рис. 4. Зависимость сопротивления заземления контурных заземлений мачт ВЛ 35 кв от времени. Величина $R_{3}: 1$ - до обработки, 2 - после обработки одного вертикального заземлителя, 3 - госле обработки всех заземлителей контура.

$\overline{\text { Tаб̆uца. } 5}$

\begin{tabular}{|c|c|c|}
\hline 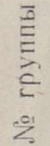 & $\begin{array}{l}\text { Удельное со- } \\
\text { противление, } \\
10^{2} \text { ом } \cdot M\end{array}$ & Тип грунта \\
\hline
\end{tabular}

\begin{tabular}{|c|c|c|}
\hline 1 & До 1 & Чернозем, глина, суглинки \\
\hline 2 & 1. -3 & $\begin{array}{l}\text { Лес, супески, глина с со } \\
\text { держанием влаги до } 40 \%\end{array}$ \\
\hline 3 & $3-5$ & Пески, пески с галькой \\
\hline 4 & $5-10$ & $\begin{array}{l}\text { Сухие пески, пески с валу } \\
\text { нами }\end{array}$ \\
\hline 5 & Болсе 10 & $\begin{array}{l}\text { Степные пески прн молї } \\
\text { ности пласта более } 10 \text { м } \\
\text { глубоком стоянии грунто- } \\
\text { вых вод; мягкие грунть } \\
\text { при малой мощности слоя } \\
(1,5 \mathrm{M}) \text { на скальном осно- } \\
\text { вании }\end{array}$ \\
\hline
\end{tabular}

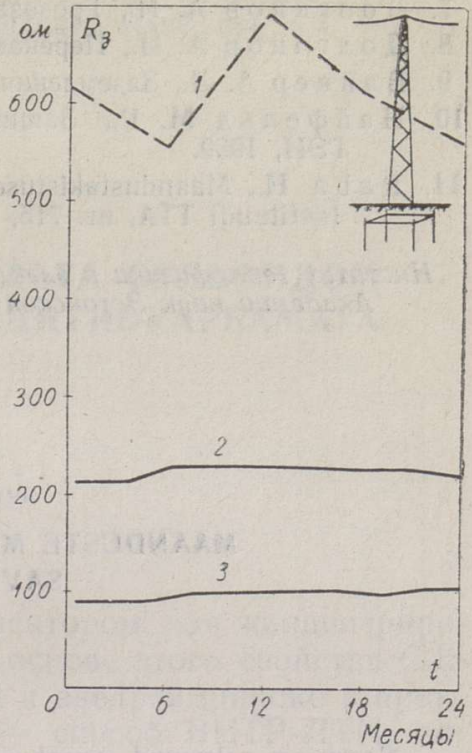

личества заземлителей при сооружении новых подстанционных заземлений и маленьком пространстве для заземления, ограниченном зданиями или другими препятствиями, но он может бєть применен и для действуюших заземлений в целях повышения их качества.

\section{Выводы}

1. Разработана методика искусственной обработки плохо проводящих почв, заключающаяся в обогащении почвы вокруг заземляющих устройств суспензией глины.

2. Методика обработки может быть применена в щелях уменьшения $R_{3}$ заземляюших устройсть как находянихся в эксплуатации, так и проектируемых. В последнем случае предварительно задаются величинами @, полученными при обработке соответствующих почв.

3. Использование органических вешеств дает возможность изменить вязкость суспензии глины и добитьея удовлетворительного ее распределения в почвах различной зернистости.

4. Двухлетние периодические измерения $R_{3}$ опытных заземляющих устройств, обработанных суспензией глины, указывают на несущественное изменение достигнутых величин $R_{3}$ под влиянием атмосферных факторов.

\section{ЛИ ТЕРА Т У РА}

1. S a nick J. H., Acta Polytechnica (Stockholm), No. 53, $41-46$ (1949).

2. Konczynski H., Prace Instytutu Lacznosci, VIII, № 3 (24), 80-81 (1961).

3. Richter A. N., Transact. South African IEE, Nov., 333-347 (1957).

4. Fritsch V., Geoelektrische Baugrunduntersuchung, Berlin, 1960.

5. Тодоров Т., Научн. тр. Н.-и. ин-та охраны труда и проф. заболеваний (Болгария), № 2, 73-79 (1960).

6. Jensen C., Electr. Eng., Feb., 68-74 (1945). 
7. Долгинов А. И., Грозозащита электрических установок, ГЭИ, 1954.

8. Долгинов А. И., Перенапряжения в электрических системах, ГЭИ, 1962.

9. В а йн ер А. Л., Заземления, ГОНТИ, 1938.

10. Н а й фельд М. Р., Защитные заземления в электротехнических установках, ГЭИ, 1959.

11. R a b a H., Maandustakistuse vähendamine katsemaandustel. ENSV TA Energeetika Instituudi TTA, nr. 715, 1961. (Ротапрннт).

Ннститут термофизики и элекгрофизики Академии наук Эстонской ССР
Поступнда в редакцию

24. I 1964

\title{
MAANDUSTE MAANDUSTAKISTUSE VÄHENDAAINE SAVISUSPENSIOONIDE ABIL
}

\author{
H. Raba \\ Resümee
}

Nagu on selgunud, annab savisuspensioonide kasutamine maanduste maandustakistuse vähendamisel väikese elektrijuhtivusega pinnastes märksa paremaid tulemusi kui seni kasutatud keedusool ja teised kemikaalid. Savisuspensioonid võimaldavad veevarustuse vee baasil vähendada maandustakistust keskmiselt 3-kordselt. Savisuspensioonide kolloidsete omaduste aktiviseerimise teel osutub aga vöimalikuks vähendada maandustakistuse suurust 5-kordselt ja veel enam. Artiklis esitatakse liivaste pinnaste töötlemise meetod savisuspensioonide abil ja andmed suspensioonidega töödeldud üksik- ja kontuurmaanduste maandustakistuse muutumise kohta kahe aasta jooksul.

Eesti NSV Teaduste Akadeemia

Termofüüsika ja Elektrofüüsika Instituut
Saabus toimetusse

24. I 1964

\section{UBER DAS VERRINGERN DES WIRKWIDERSTANDES DER ERDEN MIT HILFE VON SUSPENSIONEN}

\author{
H. Raba
}

\section{Zusammenfassung}

Es ist bekannt geworden, dass der Gebrauch von Suspensionen zwecks Verringern des Wirkwiderstandes der Erden in Böden mit kleinem elektrischem Leitwert durchaus bessere Resultate erweist, als das bisher verwendete Kochsalz und andere Chemikalien. Suspensionen aus Lehm und Trinkwasser ermöglichen ein Verringern des Wirkwiderstandes etwa dreimal. Durch Aktivisieren kolloidischer Eigenschaften von Suspensionen wird aber ein Verringern des Wirkwiderstandes der Erden über fünfmal erzielt. Im Artikel wird in Methode zur Bearbeitung sandiger Böden mit Suspensionen gegeben und Resultate über das Benehmen der Grösse des Wirkwiderstandes mit Suspensionen bearbeiteter einzelner Erden und Erdungskonturen bei einer Messperiode von 2 Jahren veröffentlicht.

Institut für Thermophysik und Elektrophysik der Akademie der Wissenschaften der Estnischen SSK
Eingegangen am 24. Jan. 1964 